\title{
Addictive agents and intracranial stimulation (ICS): Morphine, naloxone, and pressing for amygdaloid ICS
}

\author{
SARA E. CRUZ-MORALES \\ Universidad Nacional Autonoma de Mexico, Mexico, D.F., Mexico \\ and \\ LARRY D. REID \\ Rensselaer Polytechnic Institute, Troy, New York 12181
}

\begin{abstract}
Rats fixed with chronically indwelling bipolar electrodes pressed daily for intracranial stimulation (ICS) of the amygdaloid region. After pressing rates stabilized, rats were given morphine $(10 \mathrm{mg} / \mathrm{kg}, 3 \mathrm{~h}$ before a test session). Subsequently, they were given naloxone $(10 \mathrm{mg} / \mathrm{kg}$, 15 min before a test session). Morphine increased pressing for ICS and naloxone decreased pressing compared with pressing under placebo. Pressing for amygdaloid ICS is, therefore, modified by these opioids in the same way as pressing for a number of other sites of ICS.
\end{abstract}

This note is an addendum to Stapleton, Merriman, Coogle, Gelbard, and Reid (1979). The results of that work and the work of others (e.g., Adams, Lorens, \& Mitchell, 1972; Belluzzi \& Stein, 1977; Esposito \& Kornetsky, 1978) show that, under certain conditions, morphine enhances pressing for intracranial stimulation (ICS) and naloxone suppresses pressing for ICS. The doses of morphine that enhance pressing for ICS are those that subjects might self-administer or doses combined with procedures of testing that mimic the effects of self-administered doses (Reid, Lind, Bozarth, Merriman, \& Stapleton, 1978). The doses of naloxone that suppress pressing in opioid-naive rats can be quite small (less than $1 \mathrm{mg} / \mathrm{kg}$ ) (Belluzzi \& Stein, 1977; and unpublished observations from our laboratory).

Morphine's enhancement of pressing for ICS has been shown for a wide variety of anatomical focuses, including the lateral hypothalamic area, accumbens nucleus, the periaqueductal gray area, and substantia nigra. Naloxone's suppressive effects have been demonstrated with the same focuses (Stapleton et al., 1979). The amygdaloid area shows dense autoradiographic localization of opiate receptors (Atweh \& Kuhar, 1977). ICS of the amygdaloid area will sustain barpressing (Wurtz \& Olds, 1963). Morphine and naloxone have not been tested with subjects pressing for amygdaloid ICS. We now report evidence that morphine can enhance, and naloxone suppress, pressing for ICS of the amygdaloid area.

Even though opioids reliably modify pressing for ICS of many widely distributed focuses of stimulation, press-

This work was supported by a scholarship to Sara E. CruzMorales from Consejo Nacional de Ciencia y Technologia, Mexico, and special funds made available by the Rensselaer Polytechnic Institute. ing for some sites within an area of ICS is hardly modified by doses clearly changing pressing for other sites (Leibman \& Segal, 1976). These individual differences may be due to slight differences in exact focus of stimulation, to broader individual differences in reactivity of a subject to opioids, or to an interaction between these two classes of variables. As with other focuses of ICS, responsiveness to opioids differed widely with respect to pressing for amygdaloid ICS.

\section{METHOD}

Subjects

Under pentobarbital anesthesia, four male albino rats were each fixed with a chronically indwelling bipolar electrode (Plastic Products). The strands of the electrodes were insulated except at the cross section of the tip and separated from each other only by the insulation. The rats weighed $200-250 \mathrm{~g}$ at the time of the surgery.

The stimulating tip of the electrodes was aimed for the central and medial amygdaloid nuclei (Köning \& Klippel, 1963). Subsequent analysis showed that the electrode tips were, indeed, within the region of these nuclei. Following surgeries, each rat was maintained in an individual cage, with food and water always available.

\section{Apparatus}

A clear plastic box $(30 \times 24 \times 35 \mathrm{~cm})$ equipped with a lever was used; it was housed in a lighted, sound-attenuating box. The depression of the lever delivered a $.25-\mathrm{sec}$ train of $60-\mathrm{Hz}$ sine waves at various intensities, but always less than 30 microA. The number of presses was recorded automatically at the end of each 5-min period, during 1-h daily testing sessions.

\section{Procedure}

After at least 5 days for recovery from the surgery, the subjects were shaped to press for ICS, and an intensity was determined to be used throughout the remaining tests. Since ICS of the amygdala frequently engenders seizures, relatively low intensities of ICS were selected. Nevertheless, seizures occurred, and 
when they occurred, testing was suspended until the rats returned to pressing.

The subjects were trained until the response rates stabilized. Stabilization was achieved when the average of 3 consecutive days did not differ more than $10 \%$ from responding on the next day. After stabilization and across the next 6 days, the subjects were injected $3 \mathrm{~h}$ before the testing session with morphine sulphate $(10 \mathrm{mg} / \mathrm{kg}$, ip). Across the following 5 days, the subjects received saline solution in doses of the same volume $(1 \mathrm{ml} / \mathrm{kg}$, ip). The subjects were then injected with naloxone $(10 \mathrm{mg} / \mathrm{kg}$, ip) $15 \mathrm{~min}$ before testing on 5 consecutive days. Finally, across the next 5 days, all the subjects received saline injections $(1 \mathrm{ml} / \mathrm{kg})$. At the end of behavioral testing, the subjects were sacrificed with an overdose of pentobarbital and perfused first with saline and then with $10 \%$ formaldehyde. Subsequently, the brains were taken and sectioned. As an aid in determining the position of electrode tips, sections were treated as photographic negatives, and enlarged (10x) photographs were made.

\section{RESULTS AND DISCUSSION}

Pressing rates did not reliably differ across days of baseline and days when placebo injections were given. We took, therefore, the mean of all pressing across baseline and placebo tests to represent press rates when subjects were not under the influence of opioids. Pressing was modified similarly across the 5 min of each testing. Consequently, only mean pressing rates across a daily session are reported here.

Under baseline and placebo and across all subjects and 5 -min tests, the mean presses per 5 min was 198 . Under morphine, the mean presses per $5 \mathrm{~min}$ was 308 . Under naloxone, the mean presses per 5 min was 58 .

All subjects' mean response rates were higher under morphine than under placebo, but subjects differed considerably in the extent of the increase, with one subject showing an $11 \%$ increase and another showing a 59\% increase. A t test for correlated measures of the scores from placebo and morphine tests yielded $t(3)=2.45$ $(\mathrm{p}<.05$, one-tailed test $)$.

All subjects' mean response rates were lower under naloxone, with one subject showing a 52\% decrease and another showing a $90 \%$ decrease. A t test comparing scores from placebo and naloxone tests yielded $t(3)=3.40(p<.02$, one-tailed test $)$. A t test comparing scores from naloxone and morphine tests yield a $\mathrm{t}(3)=3.81(\mathrm{p}<.02$, one-tailed test $)$.

The subjects' press rates were low compared with pressing for ICS of the lateral hypothalamus, a result confirming the data presented by Wurtz and Olds (1963) using rats and by Porter, Conrad, and Brady (1959) using monkeys. The subjects frequently had seizures (when seizures occurred, recording of pressing was suspended). Morphine injections seemed to induce a slight increase in number of seizures, but naloxone had no discernible effect. We may have missed, however, instances of brief seizures. In the time period from injection of morphine to the time of testing, the subjects were often observed to be eating or gnawing.

The magnitude of the change under the influence of the drugs is greater than that seen with other sites of ICS (Stapleton et al., 1979). This may be due to the low rates of baseline or to the fact that the amygdaloid area is particularly reactive to opioids. Perhaps measures of threshold change would allow some conclusions with respect to whether the amygdaloid area is particularly reactive to these drugs.

Although it is clear that, within a region in which electrodes are placed, there are individual differences in reactivity to morphine and naloxone, mean press rates with every region tested are increased by appropriate doses of morphine and decreased by doses of naloxone. Such a result leads to the suggestion that there is a component to the "intracranial reinforcement system" that is endorphinergic. These data, therefore, add to a growing body of evidence (e.g., Esposito \& Kornetsky, 1978; Rossi \& Reid, 1976; Stapleton et al., 1979) supporting the proposition that there is concordance between the capacity of opioids to be reinforcing (addicting?) and the neurophysiology of intracranial reward.

\section{REFERENCES}

Adams, W. J., Lorens, S. A., \& Mitchell, C. L. Morphine enhances lateral hypothalamic self-stimulation in the rat. Proceedings of the Society for Experimental Biology and Medicine, 1972, 140, 770-771.

Atwen, S. F., \& KWhaR, M. J. Autoradiographic localization of opiate receptors in rat brain. III. The telencephalon. Brain Research, 1977. 134, 393-406.

Belluzzi, J. D., \& Ste in, L. Enkephalin may mediate euphoria and drive-reduction reward. Nature, 1977, 266, 556-558.

Esposito, R., \& Kornetsky, C. Opioids and rewarding brain stimulation. Neuroscience and Biobehavioral Reviews, 1978, 2. 115-122.

Köning, J. F. R., \& Klippel, R. A. The rat brain: $A$ stereotaxic atlas of the forebrain and lower parts of the brain stem. Baltimore: Williams \& Wilkins, 1973.

Liebman, J. M., \& Segal, D. S. Lithium differentially antagonizes self-stimulation facilitated by morphine and $(+)-$ amphetamine. Nature, 1976, 260, 161-163.

Porter, R. W., Conrad, D., \& Brady, J. V. Some neural and behavioral correlates of electrical self-stimulation of the limbic system. Journal of the Experimental Analysis of Behavior, 1959, 2, 43-55.

Reid, L. D., Lind, M. D., Bozarth, M. A., Merriman, V. J., \& Stapleton, J. M. Small doses of morphine sulfate and pressing for hypothalamic intracranial stimulation (ICS) in rats. Society for Neuroscience Abstracts, 1978, 4, 501. (Abstract)

Rossi, N., \& REID, L. D. Affective states associated with morphine injections. Physiological Psychology, 1977, 5, 73-75.

Stapleton, J. M., Merriman, V. J., Coogle, C. L., Gelbard, S. D., \& REID, L. D. Naloxone reduces pressing for intracranial stimulation of sites in the periaqueductal gray area, accumbens nucleus, substantia nigra and lateral hypothalamus. Physiological Psychology, 1979, 7, 427-436.

Wurtz, R. H., \& OLDS, J. Amvgdaloid stimulation and operant reinforcement in the rat. Journal of Comparative and Physiological Psychology, 1963, 56, $941-949$.

(Receited for publication July 28. 1980.) 